\title{
LHCGR Missense Mutation
}

National Cancer Institute

\section{Source}

National Cancer Institute. LHCGR Missense Mutation. NCI Thesaurus. Code C158721.

A point mutation in the LHCGR gene that encodes an amino acid substitution in the lutropin-choriogonadotropic hormone receptor protein. 